\title{
Cochrane Corner: Ocriplasmin—why isn't it being used more?
}

\author{
Michael Grinton ${ }^{1} \cdot$ David H Steel $^{1}$
}

Received: 24 February 2019 / Accepted: 1 March 2019 / Published online: 2 April 2019

(c) The Royal College of Ophthalmologists 2019

\begin{abstract}
Introduction by Jennifer Evans, Eye Specialist Editor and Joint Co-ordinating Editor for Cochrane Eyes and Vision.

Cochrane Eyes and Vision published a systematic review "Ocriplasmin for symptomatic vitreomacular adhesion" in October 2017 [1]. The review authors identified four randomised controlled trials and found high-certainty evidence that ocriplasmin treatment was more likely to result in the release of vitreomacular adhesion within 28 days and more likely to result in macular hole closure. There was also moderate-certainty evidence of benefit to visual acuity at 6 months and reduction in the requirement for vitrectomy. Adverse events were more common in eyes treated with ocriplasmin with the most frequently observed adverse events being vitreous floaters, photopsia and injectionrelated eye pain. In this inaugural Cochrane Corner for Eye, Michael Grinton and David Steel explore the reasons why ocriplasmin is not used more widely.
\end{abstract}

As part of normal human ageing, vitreous separation occurs first perifoveally, with later spontaneous vitreofoveal separation. Vitreomacular traction (VMT) is the term given to the tractional changes observed when there is persistent and pathological attachment of the vitreous cortex to the fovea during this process. Until the advent of Ocriplasmin (Jetrea; ThromboGenics, Leuven, Belgium) the only management options for symptomatic VMT and full-thickness macular hole $(\mathrm{FTMH})$ were observation or pars plana vitrectomy surgery.

Ocriplasmin (OCP) is a truncated recombinant form of human plasmin and was first approved for use in the UK by the National Institute for Health and Care Excellence (NICE) in 2013 for adults with symptomatic VMT,

Michael Grinton

Michael.Grinton@gmail.com

1 Sunderland Eye Infirmary, Queen Alexandra Road, Sunderland SR2 9HP, UK including when associated with a FTMH [1]. The efficacy of OCP was demonstrated in two phase three clinical trials (the MIVI-TRUST study group) [2] and there was significant interest in the drug in the initial years following its approval by NICE. More recently the use of OCP has waned and it now seems to be rarely offered as a treatment option. A survey of 117 members at the 2017 British and Eire Association of Vitreoretinal Surgeons (BEAVRS) meeting revealed only seven $(6 \%)$ would initially opt for OCP in the treatment of symptomatic VMT. This would seem to contradict the findings of the 2017 Cochrane Review [3] on the use of OCP. This reported a highcertainty of evidence that the drug successfully released vitreous adhesion and closed macular holes. The question therefore arises whether this apparent step away from the use of OCP is warranted or should we be both offering and using this evidence-based treatment more often?

A number of factors have potentially influenced the low uptake of OCP. One is the relatively low and variable success rate in achieving VMT release of around 30-40\% $[2,4]$, compared to vitrectomy at $\sim 100 \%$. Indeed, although the evidence behind the efficacy of OCP is comprehensive, there still remains a significant variability in the reported success rate (range 0-71\% [4]) which is thought to be largely due to case mix. A range of positive predictive factors have now been reported including age less than 65 years (odds ratio (OR) 2.7), phakic eyes (OR: 3.0), adhesion diameter $<1500 \mu \mathrm{m}$ (OR: 7.9), and absence of epiretinal membrane (ERM) (OR: 4.8) [4]. NICE took this evidence into account and recommended OCP to be used only in the absence of ERM [1]. However, the threshold for 'the presence of ERM' is not clearly defined. Indeed, in the OASIS trial the prevalence of ERM as defined by the investigators was $0 \%$ as compared to the central optical coherence tomography (OCT) reading centre who found its presence in 23\% [5]. Spectral domain OCT, with its greater resolution allows a higher prevalence of ERM in VMT cases to be identified and is also leading to the identification of new OCT features including macular hole shape [6] and detailed 
classification systems of VMT [7] that may help predict treatment success.

One argument towards the use of OCP is its relative simplicity and the avoidance of the more major option of vitrectomy surgery, and its associated complication rate. However, the use of OCP is not without risks. The Cochrane Review on OCP revealed more ocular adverse events with OCP compared with placebo or sham treated eyes [3]. The most common adverse events were vitreous floaters $(22 \%)$, photopsia (16\%) and injection-related eye pain (14\%) [3]. Long-term follow-up of patients with these symptoms show that most are of short duration, mild to moderate severity and transient [5]. However visual impairment occurring within the first 7 days of the injection has been reported in up to $12 \%$ of eyes [5]. Ninety-one percentage of these patients had resolution of their symptoms with a median time of 15 days [5] but in a small proportion of patients, a more dramatic reduction in vision has been reported [8].

With regards to OCP being a treatment, which can help avoid the risks and associated post-operative restraints of surgery, recent advances have meant that this has become less of a concern. Improved vitrectomy technology has lowered surgical morbidity with more rapid patient recovery [9]. Prolonged face-down posturing after macular hole surgery, is now known to be unnecessary in many cases [10]. The high incidence of developing a cataract post vitrectomy [11] is also no longer seen as a major disincentive with the widespread adoption of combined phacovitrectomy, and the acceptance of cataract surgery as a quick and safe procedure with the added bonus of being able to correct refractive errors. It should also be remembered that only $7-28 \%$ of macular holes presenting to Ophthalmologists are eligible for OCP treatment using the criteria of the presence of VMT and having a minimum linear diameter of less than $400 \mu \mathrm{m}$. The percentage falls to $4-16 \%$ if a size of less than $250 \mu \mathrm{m}$ is used [12, 13], where the hole closure rate with OCP approximately doubles from 25 to $50 \%$ [2,5]. Another specific concern is that OCP can increase the size of macular holes in those patients unsuccessfully treated [3], which may affect the visual result after subsequent 'rescue' surgery, although these concerns have not been proven [14].

A further factor is the evolving and competing option of pneumatic vitreolysis by the intravitreal injection of expansile gas [15]. A meta-analysis of nine case series found a release rate of $\sim 50 \%$ making it a potential low cost rival to OCP, but with no randomised controlled trials (RCTs) to definitively guide its use to date [16].

Finally it is also important to consider the overall approach to managing VMT and particularly the fact that VMT resolves spontaneously in $\sim 30 \%$ of patients $[17,18]$. Importantly there is significant overlap between the predictive factors for OCP success and those for spontaneous resolution of VMT $[4,19]$. As with OCP success, spontaneous release is hard to predict and the optimal time frame for observation before initiating treatment is unclear. Furthermore although metamorphopsia and lower quality of life scores are highly prevalent in patients with VMT [20], the fact that the condition is often unilateral and the potential rare but significant side effects of treatment, means that observation may be seen as an attractive option. Certainly the possibility of observation, weighed up against the lower success rate of a relatively less invasive procedure (OCP) or the higher success rate of a more invasive procedure (vitrectomy) is an important discussion.

The situation, as with most clinical scenarios is thus complex. Enzymatic vitreolysis with OCP represents an option to release VMT and close some FTMHs. Further research designed to guide treatment decision making regarding the timing of intervention and the role of positive predictive factors both for spontaneous and OCP mediated release would be beneficial for practicing clinicians. Large RCTs would augment our current understanding of the relative efficacy and safety of OCP as compared to other evolving options.

\section{Compliance with ethical standards}

Conflict of interest DHS is a consultant to Alcon and Oxurion. The remaining author declares that he has no conflict of interest.

Publisher's note: Springer Nature remains neutral with regard to jurisdictional claims in published maps and institutional affiliations.

\section{References}

1. National Institute for Health and Care Excellence (NICE). Ocriplasmin for treating vitreomacular traction: Technology appraisal guidance. Available from: nice.org.uk/guidance/ta297. 2013.

2. Stalmans P, Benz MS, Gandorfer A, Kampik A, Girach A, Pakola $\mathrm{S}$, et al. Enzymatic vitreolysis with ocriplasmin for vitreomacular traction and macular holes. N Engl J Med. 2012;367:606-15.

3. Neffendorf JE, Kirthi V, Pringle E, Jackson TL. Ocriplasmin for symptomatic vitreomacular adhesion. Cochrane Database Syst Rev2017, Issue 10. Art. No.: CD011874. https://doi.org/10.1002/ 14651858.CD011874.pub2.

4. Chatziralli I, Theodossiadis G, Xanthopoulou P, Miligkos M, Sivaprasad S, Theodossiadis P. Ocriplasmin use for vitreomacular traction and macular hole: a meta-analysis and comprehensive review on predictive factors for vitreous release and potential complications. Graefes Arch Clin Exp Ophthalmol. 2016;254:1247-56.

5. Dugel PU, Tolentino M, Feiner L, Kozma P, Leroy A. Results of the 2-year ocriplasmin for treatment for symptomatic vitreomacular adhesion including macular hole (OASIS) randomized trial. Ophthalmology. 2016;123:2232-47.

6. Steel DH, Parkes C, Papastavrou VT, Avery PJ, El-Ghrably IA, Habib MS, et al. Predicting macular hole closure with ocriplasmin based on spectral domain optical coherence tomography. Eye (Lond). 2016;30:740-5. 
7. Steel DH, Downey L, Greiner K, Heimann H, Jackson TL, Koshy $\mathrm{Z}$, et al. The design and validation of an optical coherence tomography-based classification system for focal vitreomacular traction. Eye (Lond). 2016;30:314-24.

8. Fahim AT, Khan NW, Johnson MW. Acute panretinal structural and functional abnormalities after intravitreous ocriplasmin injection. JAMA Ophthalmol. 2014;132:484-6.

9. González-Saldivar G, Chow DR. Update in vitreoretinal instrumentation. US Ophthalmic Rev. 2018;11:98-102.

10. Madi HA, Masri I, Steel DH. Optimal management of idiopathic macular holes. Clin Ophthalmol. 2016;10:97-116.

11. Feng H, Adelman RA. Cataract formation following vitreoretinal procedures. Clin Ophthalmol. 2014;8:1957-65.

12. Madi HA, Dinah C, Rees J, Steel DH. The case mix of patients presenting with full-thickness macular holes and progression before surgery: implications for optimum management. Ophthalmologica. 2015;233:216-21.

13. Moisseiev J, Moroz I, Katz G. Effect of ocriplasmin on the management of macular holes: assessment of the clinical relevance of ocriplasmin. JAMA Ophthalmol. 2014;132:709-13.

14. Alberti M, la Cour M. Is visual acuity non-inferior in full-thickness macular holes treated with ocriplasmin? Acta Ophthalmol. 2016;94:e166-7.
15. Jackson TL, Steel DH. It's a gas! Pneumatic release of VMT. Eye (Lond). 2017;31:347-48.

16. Neffendorf JE, Simpson ARH, Steel DHW, Desai R, McHugh DA, Pringle E, et al. Intravitreal gas for symptomatic vitreomacular adhesion: a synthesis of the literature. Acta Ophthalmol. 2018;96:685-91.

17. John VJ, Flynn HW Jr, Smiddy WE, Carver A, Leonard R, Tabandeh $\mathrm{H}$, et al. Clinical course of vitreomacular adhesion managed by initial observation. Retina. 2014;34: $442-6$.

18. Tzu JH, John VJ, Flynn HW Jr, Smiddy WE, Jackson JR, Isernhagen BA, et al. Clinical course of vitreomacular traction managed initially by observation. Ophthalmic surg lasers imaging. Retina. 2015;46:571-6.

19. Odrobina D, Michalewska Z, Michalewski J, Dzięgielewski K, Nawrocki J. Long-term evaluation of vitreomacular traction disorder in spectral-domain optical coherence tomography. Retina. 2011;31:324-31.

20. Patel PJ, Steel DH, Hirneiß C, Brazier J, Aly A, Lescrauwaet B, MeMo Study Group. Patient-reported prevalence of metamorphopsia and predictors of vision-related quality of life in vitreomacular traction: a prospective, multi-centre study. Eye (Lond). 2019;33:435-44. 